\title{
REGIONAL COMMUNITY AND INTERNATIONAL RELATIONS: THE VOLGOGRAD REGION EXPERIENCE
}

\author{
Richard A. Danakari \\ Doctor of Sciences (Philosophy), Associate Professor, \\ Professor of Department of Philosophy and Sociology, \\ Russian Presidential Academy of National Economy and Public Administration (Volgograd Branch) \\ rdanakari@mail.ru \\ Gagarina St., 8, 400013 Volgograd, Russian Federation
}

\section{Lyudmila A. Komleva}

Candidate of Sciences (Philology), Associate Professor, Head of Department of Foreign Languages, Volgograd State Academy of Physical Education kaflang@mail.ru

Prosp. Lenina, 78, 400005 Volgograd, Russian Federation

\begin{abstract}
The article deals with the complex and controversial problems of the new regional communities' formation and the impact of the interethnic relations sphere on them. The author notes that the processes of interaction between representatives of different cultures and civilizations, ethnic groups and religions have become increasingly controversial and tense in the context of continuous social dynamics. Similarly to the Russian society as a whole, regional communities are in a state of transitivity. They get transformed, they acquire new qualities such as multicasting and heterogeneity, multi-ethnicity and multi-confessionalism, fragmentarity and multiculturality. This fact increases the risks and uncertainties, problematizes future prospects. National non-governmental organizations are increasingly positioning themselves as civil society institutions at the present stage of social development at the regional level. They perform a difficult dual task: on the one hand, they ensure the preservation and development of history, native language, culture, ethnic traditions, and on the other hand, they work on the integration, on the common identity and the Russian nation formation.

On the territory of the Volgograd region, largely due to the active cooperation of regional authorities and local authorities with national public associations, international and inter-confessional relations are stable. The basis of such activity is respect for history, native language, culture, tradition, religion, national dignity of all people in the region, regardless of their belonging to a certain ethnic group or religion. Over two decades of accumulated considerable experience of joint inter-ethnic dialogue and cooperation, provided tolerance and peace, harmony and mutual understanding between people of different ethnicities and religions in the country.
\end{abstract}

Key words: regional community, inter-ethnic relations, tolerance, multiculturalism, fragmentarity, integration.

УДК 323.(470.45)

ББК 66.3(2Рос-4Вог), 5

Дата поступления статьи: 09.03.2016

Дата принятия статьи: 25.03.2016

\section{РЕГИОНАЛЬНОЕ СООБЩЕСТВО И МЕЖНАЦИОНАЛЬНЫЕ ОТНОШЕНИЯ: ОПЫТ ВОЛГОГРАДСКОЙ ОБЛАСТИ}

\section{Ричард Арами Данакари}

Доктор философских наук, доцент,

профессор кафедры философии и социологии,

Российская академия народного хозяйства и государственной службы

при Президенте РФ (Волгоградский филиал) 
rdanakari@mail.ru

ул. Гагарина, 8, 400131 г. Волгоград, Российская Федерация

\section{Людмила Александровна Комлева}

Кандидат филологических наук, доцент, заведующая кафедрой иностранных языков, Волгоградская государственная академия физической культуры

kaf_lang@mail.ru

просп. им. Ленина, 78, 400005 г. Волгоград, Российская Федерация

Аннотация. В статье рассматриваются сложные и неоднозначные проблемы формирования новых региональных сообществ и влияние на них сферы межнациональных отношений. Автор отмечает, что в условиях непрерывной социальной динамики процессы взаимодействия между представителями разных культур и цивилизаций, этносов и религий приобретают все более противоречивый и напряженный характер. Как и весь российский социум, региональные сообщества находятся в состоянии транзитивности, трансформируются, обретают новые качества: многосоставности и гетерогенности, полиэтничности и поликонфессиональности, фрагментарности и мультикультуральности, что увеличивает риски и неопределенность, проблематизирует перспективы будущего. На современном этапе социального развития на региональном уровне все активнее позиционируют себя национальные общественные организации как институты гражданского общества. Они выполняют сложную двуединую задачу: с одной стороны, обеспечивают сохранение и развитие истории, родного языка, культуры, традиций этносов, а с другой - работают над интеграцией, формированием общей идентичности и российской нации.

На территории Волгоградской области межнациональные и межконфессиональные отношения носят стабильный характер во многом благодаря активному взаимодействию органов региональной власти и местного самоуправления с национальными общественными объединениями. В основе подобной деятельности лежит уважение к истории, родному языку, культуре, традициям, вероисповеданию, национальному достоинству всех жителей региона независимо от их принадлежности к определенной этнической общности или религии.

За два десятилетия работы накоплен значительный опыт совместного межнационального и межэтнического диалога и взаимодействия, обеспечены толерантность и мир, согласие и взаимопонимание между представителями различных этносов и религий. Опыт свидетельствует, что только совместное сотрудничество представителей различных этнических групп и религиозных конфессий, национальных общественных объединений создает реальные условия не только для сохранения стабильности российского общества, но и для его развития, открывает простор для будущего, а значит, и перспективы гармонизации межнациональных и межконфессиональных отношений в стране.

Ключевые слова: региональное сообщество, межэтнические отношения, толерантность, мультикультурализм, фрагментарность, интеграция.

За последние несколько десятилетий Россия, претерпев радикальную политическую, социально-экономическую и культурную трансформацию, представляет собой качественно новую сущность. В Преамбуле Конституции Российской Федерации отмечается единство истории и общей судьбы многонационального народа нашей страны [2, с. 4]. В настоящее время российский социум представляет собой сложную и гетерогенную, противоречивую и конфликтную, полиэтническую и мультикультурную общность людей. Что представляет собой региональное сообщество как неразрывная часть единого многонационального социума? В числе многих факторов, оказывающих влияние на устойчивое функци- онирование пространства бытия регионального сообщества, в данной статье рассматривается сфера межнациональных отношений.

Актуальность исследования неоднозначных процессов, идущих в региональных полиэтнических сообществах, не вызывает сомнений; они во многом детерминируют реальность, пути и перспективы развития российской цивилизации. Не секрет, что сегодня межнациональные отношения стоят в ряду тех значимых факторов, которые активно воздействуют на реальное бытие российского общества и его динамику. Согласимся с мнением B.А. Тишкова о том, что Россия - это национальное государство с многоэтничной российской нацией, основу которой составляет рус- 
ская культура и язык, в которую входят представители других российских национальностей [7, с. 121].

Одна из важных задач нашей работы изучение и фиксация реальных общественных изменений, происходящих на уровне «провинций», местных образований, непосредственной среды жизни и деятельности огромного количества людей. Не секрет, что исследование «провинциального среза» раскрывает объективную картину реальности, способствует поиску ответов на многие общероссийские «вызовы». Как известно, в полиэтническом и поликонфессиональном обществе одним из главных принципов устойчивости социальной системы является ее соответствие базовым ценностям и объективным национальным традициям.

Рассматривая соотношение целого и части, федерального и регионального, отметим, что в настоящее время на евразийском пространстве Российская Федерация является одной из самых многонациональных и поликонфессиональных государств. На ее территории проживает более 193 наций и этносов, принадлежащих к различным культурам, религиозным и языковым группам, обладающих своими традициями, обычаями, уникальным укладом жизни [9]. Подавляющее большинство из них являются аборигенными народами, ведущими своеобразный уклад жизни, имеющими свои традиции и обычаи. В.А. Тишков пишет: «Совместное проживание носителей многих культур и языков в пределах одной страны и в составе одного российского народа было характерно для нашего государства на протяжении всей его истории. Многообразие населения стало источником постоянного и взаимообогащающего общения, условием развития страны» [8, с. 7]. Однако периодические повторяющиеся кризисы создают напряженность во всех сферах общества, в том числе и в области межэтнических отношений. Наиболее часто она проявляется на региональном уровне, при этом дестабилизируется вся система общественных отношений, сфера межцивилизационного и межнационального взаимодействия местных сообществ, жизнь всех общественных структур и отдельных индивидов. Межнациональные конфликты, которые периодически проявля- ют себя на локальном уровне, свидетельствуют об их значительном влиянии на всю социальную систему, стабильное существование и динамичное функционирование всего общества. Например, сильный общественный резонанс вызвали конфликты на межэтнической почве, которые произошли 1 июля 2011 г. в поселке Сагра Свердловской области, 56 июля 2013 г. в г. Пугачеве Саратовской области, 12-14 октября 2013 г. в Бирюлево Западном в Южном административном округе Москвы.

В современном обществознании пока слабо исследуются проблемы, касающиеся влияния межэтнических отношений на трансформационные процессы регионального уровня, их корреляции с культурно-историческим целым, социальным бытием всего общества. Сегодня все региональные сообщества - это сложные и органические системы, многосоставные структуры, включающие людей разных наций и этносов, религий и конфессий, статусов, поколений, социальных групп и слоев, которые находятся в состоянии транзитивности, приобретают новое качество. В условиях существующих рисков и неопределенностей достаточно сложно проводить их аналитику, определить сущность, выявить реальные альтернативы и давать объективный прогноз, какими они будут завтра. На наш взгляд, региональное сообщество следует рассматривать не просто как замкнутую на себя единицу, а как диффузную и динамичную целостность, подверженную непрерывным изменениям под воздействием разных факторов.

Известно, что межэтнические отношения, вопросы национального бытия являются очень тонкой материей, чутко реагирующей на любые изменения в общественной системе, поэтому региональное управление данными процессами должно проводиться умело и профессионально, чтобы найти баланс, грани между традициями и инновациями. Очевидно, что опора на традиции и их исключительность, консервация ценностей может привести не только к новым противоречиям и напряженности, но и сопровождаться социальными и культурными конфликтами и издержками.

Обращение к этнической специфике и вопросам обеспечения стабильности предполагает отсылку к общемировым тенденциям. 
Продолжающийся этнический и религиозный ренессанс в мире, напряженность в межнациональных отношений в России, неудачи политики мультикультурализма и концепции «плавильного котла» в развитых странах придают данной проблеме актуальный и злободневный характер. Если говорить о региональных сообществах, то дальнейшая их этнизация и конфессионализация, наступление этничности и религии на все сферы общества создают серьезные проблемы для современных многонациональных государств. Тревожным является то, что все эти процессы происходят в условиях продолжающегося расслоения и деградации социума, его культуры, нравственности. Справедливым представляется мнение О.М. Цветкова, когда он, актуализируя принцип единства в многообразии, пишет о том, что «жизнеспособность гражданской нации зависит от благополучия составляющих ее этнонаций» $[10$, с. 205].

Сегодня все наши региональные сообщества находятся на разных стадиях цивилизационного и культурного развития, характеризуются многообразием экономических, социальных, культурных, этнических и конфессиональных различий. Этнические процессы протекают в существенно отличающихся условиях, подвергаются воздействию различных внутренних и внешних причин, имеют неодинаковую интенсивность, векторы и направления развития. Сложность в том, что в современных социальных процессах, в том числе и регионального уровня, одновременно присутствуют процессы полиэтнизации и диаспоризации, этнической стагнации и мобилизации, политизированной этничности и межэтнической конфронтации.

В Стратегии государственной национальной политики органам регионального управления отводится особая роль. Они призваны выражать разнообразные интересы жителей субъекта и способствовать более гибкому учету их этнических и культурных запросов, создавать атмосферу мира и согласия, заниматься на местном уровне формированием межнациональной толерантности, позитивного отношения к культуре, традициям и обычаям народов страны. На них возложена обязанность по созданию условий для осуществления деятельности, связанной с реализацией прав местных национально-культурных автономий, оказанию содействия национальнокультурному развитию народов Российской Федерации, реализации мероприятий в сфере межнациональных отношений [9].

Рассматривая Волгоградский мегаполис, отметим, что с момента своего возникновения, становления и развития он отличается полиэтническим и поликонфессиональным составом населения. Хотя подавляющее большинство населения города и области составляют русские, наш регион остается в числе самых многонациональных и поликонфессиональных субъектов России, где существуют давние традиции совместного и компактного проживания коренных этносов. Сегодня на территории области проживают представители более 140 народов, в том числе 23 наиболее многочисленных национальностей. Это русские, украинцы, казахи, немцы, татары, евреи, чеченцы, чуваши, азербайджанцы, грузины, представители народов Дагестана, корейцы, армяне, поляки, таджики, узбеки, башкиры, калмыки, мордовцы, удины и другие. Русские как основной по численности этнос определяют этнокультурную ситуацию в Волгоградском регионе, доминируют во многих социальных процессах области. Проблема заключается в том, что доминирующее большинство, как правило, ассоциирует себя с универсальными, общечеловеческими, а не со специфически этническими ценностями, и поэтому его этническое самосознание неизбежно ослаблено [11, с. 70]. Вследствие этого оно не нуждается в постоянном выражении своих этнических претензий, идентичности, как это делают этнические меньшинства.

Отметим, что в настоящее время на территории Волгоградской области числится 65 зарегистрированных в установленном порядке национальных общественных объединений и 3 незарегистрированные, но осуществляющие свою деятельность [4].

За последние десятилетия в России, в том числе и в нашем регионе, отмечается значительный рост национального самосознания граждан, что обусловило резкую актуализацию их социокультурных потребностей по сохранению и развитию языка, истории, национальной культуры, образования, самобытности, традиций и обычаев. Жители области, 
представляющие различные национальности, стремятся сохранить языковые и культурные особенности своего народа, создать условия для их передачи молодому поколению, развивать исторические традиции, накопленные предками.

Отметим, что еще в 90-е гг. XX в. для гармонизации межэтнических отношений и тесной работы с этническими диаспорами, формирующимися национальными объединениями был создан областной Комитет по делам национальностей и казачества. Была разработана и многие годы активно реализовывалась программа «Социально-экономического и этнокультурного развития населения Волгоградской области». Значимой формой взаимодействия власти и национальных общественных объединений как институтов гражданского общества можно считать деятельность общественных советов. В нашем регионе уже долгое время активно функционирует Общественный совет при Комитете по делам национальностей и казачества Волгоградской области, обладающий правом выдвигать и поддерживать гражданские инициативы.

За два десятилетия работы накоплен значительный опыт совместного межнационального и межэтнического диалога и взаимодействия, обеспечены толерантность и мир, согласие и взаимопонимание между представителями различных этносов и религий. Анализ выявил, что только совместная работа, сотрудничество представителей различных этнических групп, национальных общественных объединений и религиозных конфессий создает условия для сохранения стабильности и устойчивого развития социума.

За переходный период и последние кризисные годы в Волгограде и области были реализованы значительные мероприятия. В первую очередь обеспечена поддержка мероприятий, проводимых национальными общественными организациями с целью создания условий для удовлетворения жителями своих этнических, религиозных и культурных потребностей и интересов, приобщения к российской культуре. Они были посвящены традиционным памятным и праздничным дням почти всех народов региона (Дни татарской культуры, День калмыцкой культуры, Дни корейской культуры, Дни немецкой культуры, День Дагеста- на, День памяти жертв геноцида армянского народа, День Греции, День Полонии, День единения славян, День памяти депортации немцев Поволжья и др.).

Комитет по делам национальностей и казачества области постоянно использует практику активного привлечения представителей разных народов и конфессий к участию в значимых городских культурно-массовых форумах. Существующие культурные центры и Центры национальных общественных объединений пользуются поддержкой органов власти всех уровней. Они оказывают помощь и поддержку деятельности всех художественных и самодеятельных коллективов, пропагандирующих общие ценности и национальные особенности культуры. Это национальный татарский ансамбль «Чешме», армянские коллективы «Артуйт» и «Арарат», украинский коллектив «Пролиски», народный ансамбль кавказских танцев «Саирме» и др. Большая часть самодеятельных коллективов представлена молодежью.

Многие национальные коллективы и группы стали непременными участниками всех крупных общегородских мероприятий, таких как День города, День Победы, День народного единства. Руководители и активисты национальных общин и религиозных конфессий периодически проводят совместные мероприятия разного характера. Уже стало традицией торжественно отмечать не только знаменательные исторические даты, но и религиозные праздники народов, такие как Рождество Христово, Пасха, Пейсах, Курбан-Байрам, Новруз, Ханука. Ежегодно на самом высоком уровне, с приглашением большой делегации из Татарстана, деятелей культуры и искусства, руководителей власти и общественных организации Волгоградской области проводится национальный праздник татар - Сабантуй.

В числе наиболее интересных и удачных проектов следует назвать выпуск уникального иллюстрированного издания - информационного справочника «Национальности и национальные общественные объединения Волгограда» [3]. В регионе налажено тесное взаимодействие с региональными и муниципальными СМИ с целью полноценного и адекватного освещения взаимодействия с нацио- 
нальными общественными объединениями и религиозными конфессиями.

В Волгоградской области накоплен огромный опыт патриотического и интернационального воспитания, который становится все более востребованным. В соответствии с государственной программой «Патриотическое воспитание граждан Российской Федерации» в регионе многое делается для укрепления славных исторических и интернациональных традиций, ведется большая воспитательная работа на примерах героизма участников Сталинградской битвы. Одновременно через систему мероприятий и занятий проводится разъяснительная работа среди студентов и школьников о недопустимости унижения и оскорбления людей на национальной или конфессиональной почве, проявления хулиганства и насилия, пропаганды вражды, ненависти и агрессии по национальному, религиозному и социальному признакам.

Анализируя деятельность Комитета по делам национальностей и казачества Волгоградской области и национальных общин региона, отметим, что она направлена на выполнение целостной двуединой задачи: с одной стороны, на сохранение и развитие истории, родного языка, культуры, традиций этносов, а с другой - формирование общекультурной идентичности, единой российской нации. Следует согласиться с мнением Э.А. Паина, когда он пишет о важности получения этническим меньшинством гарантии защиты своих прав и свобод, безопасности, удовлетворять свои этнокультурные интересы, укреплять и расширять самостоятельность автономий [5].

Сегодня наиболее активное влияние на гармонизацию сферы межэтнических отношений в нашем регионе оказывает возникшая несколько лет назад Волгоградская областная общественная организация развития культуры «Дом дружбы», возглавляемая К.Г. Фарниевым. Она представляет собой руководство и активную группу представителей большинства национальных общин, молодежь и студенчество Волгограда. В ее состав входят русские, осетины, азербайджанцы, украинцы, татары, белорусы, евреи, армяне, грузины, таджики, узбеки, удины, представители народов Дагестана и многих других этносов.
Общественная организация «Дом Дружбы» выступает как важный консолидирующий фактор в полиэтнической и поликонфессиональной среде региона. Она объединяет все народы региона, вместе с властью и общинами организует и проводит огромное количество мероприятий: государственные праздники, национальные фестивали, встречи, семинары, молодежные диспуты, субботники. Организация способствует развитию и гармонизации межнациональных отношений в русле формирования общегражданской идентичности, стремится найти единые для всего местного общества наднациональные ценности. Уникальные возможности влияния на социально-политические процессы региона видятся именно в активной работе собственного интернет-портала, радио и журнала «Дом дружбы». Отметим, что журнал «Дом дружбы» распространяется как в печатном виде, так и в сети Интернет, находится в открытом доступе.

Благодаря наличию журнала, собственного информационного ресурса, расположенного в сети Интернет, деятельность этой организации позволяет охватить большее количество реальной и потенциальной аудитории, особенно молодежи. Она прекрасно учитывает современные условия и возрастные характеристики пользователей Интернета в мире, наиболее тесно работает со студенческой молодежью.

Спецификой журнала «Дом дружбы» является подготовка научных и публицистических статей этнического и многонационального характера, освещение знаменательных дат, фестивалей, дней национальных культур, праздников, обычаев, традиций. Много внимания уделяется особенностям национального быта, ремеслам, кухне, одежде и другим характеристикам культуры этносов нашего региона. Многие события освещаются и пропагандируются в СМИ, сопровождаются презентациями с использованием старинных фотографий и исторически значимых иллюстраций. Сам журнал постоянно отчитывается перед своей аудиторией, выступает в качестве своеобразного ведущего проводимых мероприятий и других форм деятельности национальных общин. Важно отметить, что все материалы, любая информация, появившаяся в журнале, 
носит как этнический, так и наднациональный, интернациональный характер.

Среди многообразных форм деятельности, проводимых национальными общинами и «Домом Дружбы», можно выделить организацию благотворительных вечеров, концертов с участием популярных российских и местных артистов. Руководители и активисты национальных общин вместе с работниками «Дома дружбы» активно участвуют в городских и районных субботниках. В течение нескольких лет они обеспечивают высадку «аллей дружбы» не только в нашем регионе, соседних субъектах Северного Кавказа, но и в Крыму, других краях и областях Российской Федерации. В 2015 г. национальные общественные объединения с приглашением ветеранов войны из стран СНГ провели огромное количество мероприятий, посвященных 70-й годовщине Великой Победы.

Укреплению социально-политической стабильности и гармонизации межнациональных отношений в регионе особенно внимание уделяется в Волгоградском филиале Российской академии народного хозяйства и государственной службы при Президенте Российской Федерации. Уже давно такая деятельность приняла целеустремленный и системный характер, она может быть проиллюстрирована на примере ряда проведенных мероприятий. В частности, в числе важных мероприятий, проведенных за последнее годы в Волгоградском филиале РАНХиГС при активном участии работников Администрации Волгоградской области, Комитета по делам национальностей и казачества, областного центра по патриотической и поисковой работе, профессоров и преподавателей разных вузов города, был научно-практический семинар, посвященный теме: «Нижнее Поволжье - территория мира и согласия. Профилактика межэтнических конфликтов и ксенофобии в Волгоградском регионе: исторический опыт и современность» [4].

В этих целях в апреле 2014 г. был проведен «круглый стол» на тему «Национальные общественные объединения и развитие гражданского общества в России: опыт взаимодействия». Обсуждались актуальные темы: стратегия государственной национальной политики в РФ и межэтнические отношения, роль
НОО в становлении гражданского общества в России, гражданский патриотизм и гражданская идентичность, вопросы миграции и обеспечения согласия в многонациональном обществе, взаимодействие в сфере межэтнических отношений, эффективное управление и поддержка органами государственной власти и органами местного самоуправления этих процессов в Волгоградской области [1, с. 21].

Подводя итоги, отметим, что в настоящее время все национальные общественные объединения Волгоградской области основные усилия направляют на интеграцию регионального сообщества, формирование общей культуры, единых общероссийских ценностей и традиций. Поэтому не случайно, что в числе значимых мероприятий конца 2015 г. - общее заседание национальных общин под эгидой «Дома Дружбы» с целью интеграции в единую целостность. Главное задачей стало дальнейшее единство и развитие национальных культур на территории Волгограда и области, движение через многоязычие и полифонию культур к интеграции, общенациональной идентичности, обеспечение целостности государства и устойчивого развития страны.

\section{СПИСОК ЛИТЕРАТУРЫ}

1. Взаимодействие в национальной политике // Дом дружбы. - 2014. - № 23. - С. 21.

2. Конституция Российской Федерации : (принята всенародным голосованием 12 декабря 1993 г.). СПб. : Питер, 2014. -64 с.

3. Национальности и национальные общественные объединения Волгограда : информационный справочник / Комитет по делам культуры администрации Волгограда. - Волгоград, 2008. $416 \mathrm{c}$.

4. Нижнее Поволжье - территория согласия. Межнациональные и межконфессиональные отношения в Волгоградском регионе: история и современность // Материалы научно-практического семинара / под ред. И. О. Тюменцева [и др.]. - Волгоград : Изд-во ФГОУ ВПО ВАГС, 2011. - 148 с.

5. Паин, Э. А. Издержки российской модернизации: этнополитический аспект / Э. А. Паин // Общественные науки и современность. - 2005. № 1. - C. 148-159.

6. Список национальных общественных объединений Волгоградской области на 01.01.2015. Электрон. текстовые дан. - Режим доступа: www.дом-дружбы.рф. - Загл. с экрана. 
7. Тишков, В. А. Нация и национальная идентичность в России / В. А. Тишков // Вестник российской нации. - 2008. - № 1. - С. 121.

8. Тишков, В. А. Этническое и религиозное многообразие - основа стабильности и развития российского общества / В. А. Тишков // Статьи и интервью. - М. : Моск. бюро по правам человека : Academia, 2008. - 84 c.

9. Указ Президента РФ «О Стратегии государственной национальной политики Российской Федерации на период до 2025 года» от 19 декабря 2012 г. № 1666. - Доступ из информ.-правового портала «ГАРАНТ».

10. Цветков, О. М. Российская гражданская нация: проблемы укрепления и интеграции / О. М. Цветков // Вестник Адыгейского государственного университета. Серия 1: Регионоведение: философия, история, социология, юриспруденция, психология, культурология. - 2009. - № 3. - С. 201-206.

11. Шнирельман, В. А. Расизм, этничность, демократия: национальные модели / В. А. Шнирельман // Политическая концептология. - 2010. - № 4 . C. 70 .

\section{REFERENCES}

1. Vzaimodeystvie $\mathrm{v}$ natsionalnoy politike [Cooperation in National Politics]. Dom druzhby, 2014, no. 23, p. 21.

2. Konstitutsiya Rossiyskoy Federatsii: (prinyata vsenarodnym golosovaniem 12 dekabrya 1993 g.) [The Constitution of the Russian Federation: (Adopted by All-People Voting on December 12, 1993).]. Saint Petersburg, Piter Publ., 2014. 64 p.

3. Natsionalnosti i natsionalnye obshchestvennye obyedineniya Volgograda: informatsionnyy spravochnik / Komitet po delam kultury administratsii Volgograda [Nations and National Public Communities of Volgograd: An Information Guide. Committee on Cultural Affairs of VolgogradAdministration]. Volgograd, 2008.416 p.

4. Nizhnee Povolzhye - territoriya soglasiya. Mezhnatsionalnye i mezhkonfessionalnye otnosheniya v Volgogradskom regione: istoriya i sovremennost
[Lower Volga Region is the Territory of Consent. Interethnic and Interfaith Relations in the Volgograd Region: History and Modernity]. Tyumentsev I.O., ed. Materialy nauchno-prakticheskogo seminara [Materials of Scientific and Practical Seminar]. Volgograd, FGOUVPO VAGS Publ., 2011. 148 p.

5. Pain E. A. Izderzhki rossiyskoy modernizatsii: etnopoliticheskiy aspekt [Russian Modernization Costs: Ethnic and Political Aspect]. Obshchestvennye nauki i sovremennost, 2005, no. 1, pp. 148-159.

6. Spisok natsionalnykh obshchestvennykh obyedineniy Volgogradskoy oblasti na 01.01.2015 [The List of National Public Communities of the Volgograd Region as of January 1, 2015]. Available at: www.dom-druzhby.rf.

7. Tishkov V.A. Natsiya i natsionalnaya identichnost v Rossii [Nation and National Identity in Russia]. Vestnik rossiyskoy natsii, 2008, no. 1, p. 121.

8. Tishkov V.A. Etnicheskoe i religioznoe mnogoobrazie - osnova stabilnosti i razvitiya rossiyskogo obshchestva [Ethnic and Religious Diversity is the Basis of the Russian Society Stability and Development]. Statyi $i$ intervyu [Articles and Interviews]. Moscow, Moskovskoe byuro po pravam cheloveka Publ.; Academia Publ., 2008. 84 p.

9. Ukaz Prezidenta $R F$ "O Strategii gosudarstvennoy natsionalnoy politiki Rossiyskoy Federatsii na period do 2025 goda" ot 19 dekabrya 2012 g. № 1666 [The Decree of President of the Russian Federation "On the Strategy of State National Policy of the Russian Federation for the Period Till 2025" of December 19, 2012 no. 1666]. Access from Information Legal Portal "Garant".

10. Tsvetkov O.M. Rossiyskaya grazhdanskaya natsiya: problemy ukrepleniya i integratsii [Russian Civic Nation: Strengthening and Integration Problems]. Vestnik Adygeyskogo gosudarstvennogo universiteta. Seriya 1: Regionovedenie: filosofiya, istoriya, sotsiologiya, yurisprudentsiya, psikhologiya, kulturologiya, 2009, no. 3, pp. 201-206.

11. Shnirelman V.A. Rasizm, etnichnost, demokratiya: natsionalnye modeli [Racism, Ethnicity, Democracy: National Models]. Politicheskaya kontseptologiya, 2010, no. 4, p. 70. 